\title{
Electrical properties of muscle fibre membranes in man
}

\author{
A. J. McCOMAS, K. MROŻEK ${ }^{1}$, D. GARDNER-MEDWIN, AND \\ W. H. STANTON ${ }^{2}$
}

From the Department of Physiology, University of Newcastle upon Tyne, and Muscular Dystrophy Research Laboratories, Newcastle General Hospital

During recent years a number of investigations have been concerned with the measurement of the resting membrane potential in human skeletal muscle fibres (Johns, 1960; Elmqvist, Johns, and Thesleff, 1960; Norris, 1962; Creutzfeldt, Abbott, Fowler, and Pearson, 1963; Bolte, Riecker, and Röhl, 1963; Goodgold and Eberstein, 1966; Höfmann, Alston, and Rowe, 1966; Ludin, 1967; Brooks and Hongdalarom, 1968).

The present paper has two aims. Firstly, it assesses the merits and disadvantages of the various types of intracellular recording technique which have been employed. Secondly, it presents the results of a new study in which intracellular stimulation enabled additional information about the electrical properties of the muscle fibre membrane to be obtained. The present results have been compared with those from earlier studies in the mouse made in this laboratory (McComas and Mossawy, 1965, 1966) and they have also served as control values for the investigation of certain human myopathies (McComas, Mrożek, and Bradley, 1968; McComas and Mrożek, 1968).

\section{METHODS}

SUBJECTS Three subjects volunteered to participate in the study; they were healthy young women who were undergoing a series of tests, including muscle biopsy, to establish whether or not they were carriers of the gene for Duchenne dystrophy (Walton and Pennington, 1966; GardnerMedwin, 1968).

Subject E.E. (age 22) was the daughter of a definite carrier. Her serum creatine kinase level of 18 i.u./1. was within normal limits (0-66.5 i.u./1.). A biopsy of the left biceps brachii disclosed no myopathic features. During electromyographic examination of the right biceps brachii muscle some polyphasic, and some short duration, motor unit potentials were detected but these constituted a mild and questionable abnormality. The serum creatine kinase level of an identical twin sister was $36 \mathrm{i} . \mathrm{u} . / 1$. The probability of her being a carrier was assessed as approximately $1: 6$.

'Present address; Department of Neurology, Medical School, Warsaw. ${ }^{2}$ Dr. W. H. Stanton has since died.
Subject A.L. (age 17) was the daughter of a definite carrier. Her serum creatine kinase titre was normal (15 $\vec{D}$ i.u./1.) and both histological and electromyographic examination of the biceps brachii muscles failed to reveal $\overrightarrow{\vec{\omega}}$ any definite abnormality. The probability of her being a $\omega$ carrier was therefore approximately 1:6.

Subject A.B. (age 26) was the daughter of a definite carrier. She had a markedly elevated serum creatine kinase level (1,466 i.u./1.). A biopsy of the left quadriceps $\overrightarrow{i r}$ revealed evidence of myopathy; electromyography of the opposite quadriceps and of the right biceps muscles dis closed substantial proportions of motor unit potentiag which were either polyphasic or of abnormally shot duration. She was regarded as a proven carrier.

SELECTION OF MUSCLES The micro-electrode investiga tions were performed in vivo on the muscle which hag been surgically exposed for biopsy. In one of the subject. (A.B.) the left rectus femoris muscle was selected fos biopsy since the contralateral quadriceps had exhibitef definite electromyographic abnormalities. The left biceps brachii was investigated in the two normal subjects E.E. and A.L. The micro-electrode recording session lasted 30-40 minutes and the biopsy was taken immediately afterwards. All three incisions healed satisfactorily by first intention.

ANAESTHESIA The patients were given pre-operative medication with pethidine, $25 \mathrm{mg}$, and phenergan, $25 \mathrm{mg}$; general anaesthesia was achieved with nitrous oxide and halothane. No muscle relaxant drugs were given.

PREPARATION OF MUSCLES Rectus femoris The skin was sterilized and a curved Perspex plate with raised edges (Fig. 1) was then clamped down on to the surface of the thigh; a centrally-situated aperture in the plate surrounded the site on the skin intended for incision. This plate had three functions: it reduced the troublesome respiratory movement transmitted from the abdomen, it improved the general stability of the thigh, and it formed a fluid trap (see below).

A thin sterile plastic sheet (Vi-drape, Aeroplast Ltd) was then glued over both the plate and the central area of skin. An incision 2-3 in. long was made through the skin and subcutaneous tissue in the midline of the thigh. The thick connective tissue sheath investing the muscle was gently picked up with forceps, incised and retracted. The exposed surface of the muscle was covered with a pool of 


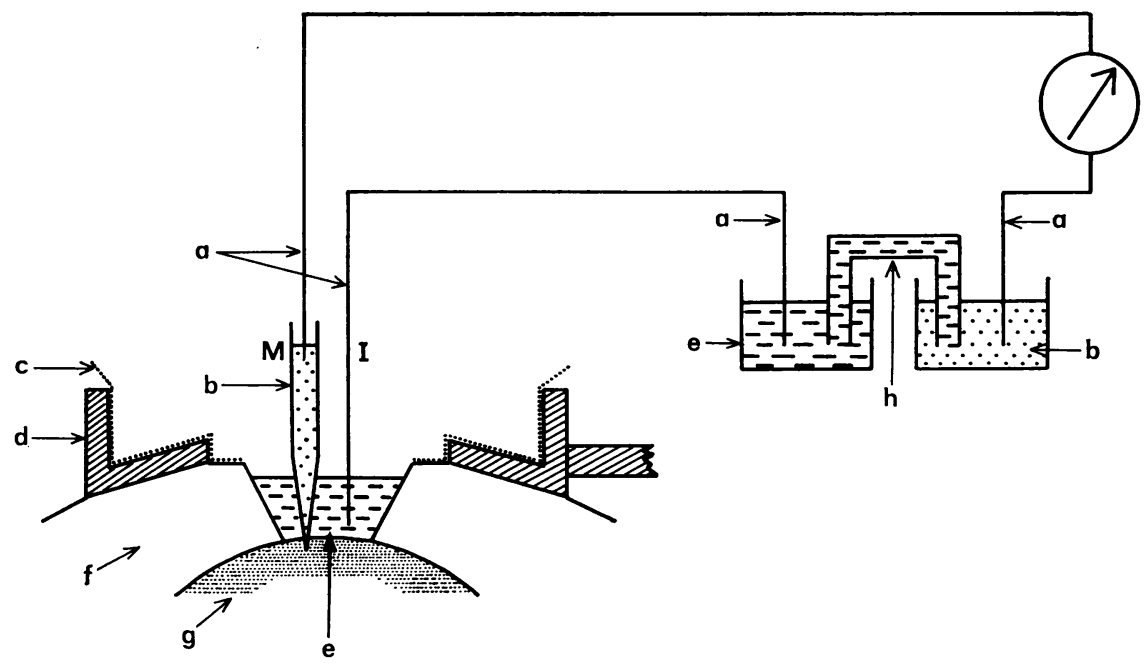

FIG. 1. Apparatus for micro-electrode investigation of human muscle; $a$, chlorided silver wire; $b, 2 \mathrm{M} \mathrm{KCl}$ solution; $c$, Vi-drape dressing; $d$, Perspex plate; e, Liley's solution; $f$, subcutaneous fatty tissue; $g$, muscle; $h$, Lileyagar bridge; $M$, microelectrode; I, indifferent electrode.

mammalian bathing solution (Liley, 1956) at room temperature $\left(18^{\circ}-20^{\circ} \mathrm{C}\right)$. Any fluid spilling over from the edges of the incision was trapped by the plastic sheet lining the raised edges of the Perspex plate. In this way the fluid was prevented from wetting the surgical towels and forming spurious leaks to earth which would have unbalanced the Wheatstone bridge circuit (see below).

Preparation of biceps brachii The biceps muscle was prepared in a similar way except that the Perspex plate was omitted. It was felt, however, that a smaller plate, made to fit the upper arm, would have improved the stabilization of this muscle and would have made it easier to avoid leakage of fluid from the incision.

STIMULATING AND RECORDING TECHNIQUE Two types of micro-electrode were used. One type had an external tip diameter of 0.5 to $1 \mu$ and was used for measurements of resting potential; it had a d.c. resistance in Liley's solution of 5-15 M $\Omega$. The second type of electrode was used for simultaneous stimulation and recording; it had a coarse (ca. $1 \mu$ ) tip to reduce electrode rectification during the passage of current (Beránek, 1964; McComas and Mossawy, 1966) and typically had a resistance of $1 \mathrm{M} \Omega$ (range 0.7 to $3 \mathrm{M} \Omega$ ). In spite of the relatively large tips of such electrodes it was often possible to effect satisfactory impalements of fibre membranes and the corresponding values of resting potential have therefore been included in the results. Both types of electrode were filled with sterile $2 \mathrm{M} \mathrm{KC1}$ solution by boiling under reduced pressure for 15 minutes. The tip potentials of the fine electrodes were usually about $10 \mathrm{mV}$, while the values for the coarse electrodes were considerably less.

A sterile chlorided silver wire was used to connect the micro-electrode to a Wheatstone bridge. Another similar wire was used as the indifferent electrode; the junction potentials in the input circuit were balanced out by the method shown in Figure 1. The Wheatstone bridge served to suppress the stimulus artefact during intracellular stimulation. It was similar to that used by McComas and
Mossawy (1966), except that a $100 \mathrm{~K} \Omega$ variable resistance was used to balance the micro-electrode resistance. The frequency response of the recording system extended from d.c. to $3 \mathrm{~dB}$ down at $20 \mathrm{kc} / \mathrm{s}$ when a $1 \mathrm{M} \Omega$ electrode was employed. After the resting potential had been measured, intracellular stimulation was carried out, using rectangular depolarizing current pulses, $10-20 \mathrm{msec}$ in duration. The following membrane parameters were determined. a. The membrane time constant $\left(\mathrm{T}_{\mathrm{m}}\right)$ : measured as the time taken for small (usually $<5 \mathrm{mV}$ ) electrotonic potentials to reach $85 \%$ of their final values (Fatt and Katz, 1951).

b. The input resistance $\left(\mathrm{R}_{\mathrm{in}}\right)$ : measured as the amplitude of the depolarization plateau divided by the total current flowing through the membrane.

c. The critical membrane potential: that is, the threshold potential for the initiation of action potentials.

d. The critical membrane depolarization: that is, the change in potential required to bring the membrane from its resting to its critical condition.

e. The amplitude of the action potentials.

The necessary measurements were made from negatives on $35 \mathrm{~mm}$ film which were projected on to squared paper. Some of the resting potentials were also made in this way; others were obtained at the time of the experiment using 'backing-off' voltages from a calibrator. The time available for stimulation was limited due to irreducible mechanical instability in the recording system. For this reason the stimuli were delivered at $100 \mathrm{msec}$ intervals from a sequence of five stimulators which had their outputs set to different levels. To avoid troublesome changes in tip potential (Nastuk and Hodgkin, 1950; Del Castillo and Katz, 1955; Adrian, 1956) and also to restrict the number of damaged fibres within the biopsy specimen, only the four most superficial fibres were investigated in each track.

Presentation of results The standard error of the mean has been used throughout the text to indicate variability within a population of observations. 
RESULTS

RESTING POTENTIAL The mean resting membrane potentials found in each of the three subjects are given in Table I while the frequencies of the observed potentials in the pooled population of fibres are shown in Figure 2.

\section{TABLE I}

RESTING MEMBRANE POTENTIALS (R.P.) PRESENTED FOR EACH OF THE THREE SUBJECTS INVESTIGATED

\begin{tabular}{llllc} 
Subject & $\begin{array}{l}\text { Provisional } \\
\text { status }\end{array}$ & Muscle & $\begin{array}{l}\text { Mean R.P. } \pm \text { S.E. } \\
(m V)\end{array}$ & $\begin{array}{l}\text { Fibres } \\
(\text { no. })\end{array}$ \\
\hline E.E. & 'Normal' & Biceps & $83.6 \pm 0.7$ & 68 \\
A.L. & 'Normal' & Biceps & $\mathbf{8 1 . 4} \pm 1.38$ & 10 \\
A.B. & 'Carrier' & Quadriceps & $\mathbf{8 4 . 0} \pm 0.8$ & 56
\end{tabular}

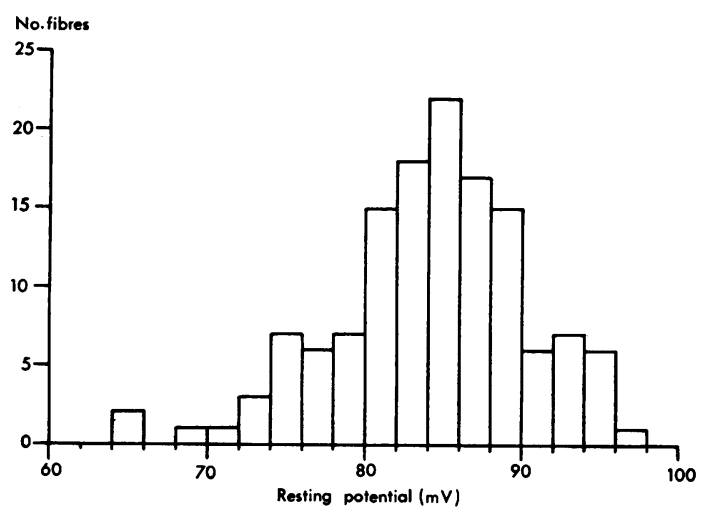

FIG. 2. Observed frequencies of resting membrane potentials among 134 fibres in three subjects; mean 83.6, S.E. $\pm 0.5 \mathrm{mV}$.

It is evident from Table $I$ that the differences in mean potential between the subjects were small and statistically they were not significant. Although only three muscles were investigated, the number of fibres sampled was sufficiently large to suggest that, in terms of resting potential and of the other membrane characteristics, the biceps and rectus femoris muscles $Z$ were functionally similar.

From Table II it can be seen that the present results fall within the range of means reported for normal human muscle by other authors. It is, how- 0 ever, apparent that this range of values is large, presumably as a result of differences in experimental $\frac{\rho}{5}$ or interpretive technique (see Discussion).

ACTION POTENTIAL For 37 normal fibres (mean resting potential $85.1 \mathrm{mV}$ ) the sizes of the critical $\stackrel{5}{\rightarrow}$ depolarizations required to bring the membrane potentials from the resting to the firing levels were measured; these results are given in Fig. $3 \mathrm{~A}$ and an $\frac{\bar{\sigma}}{\overrightarrow{0}}$ example of intracellular stimulation is shown in Fig- $\stackrel{\triangle}{\triangle}$ ure 3C. The corresponding firing levels, or critical membrane potentials, of these fibres were equal to $\overrightarrow{0}$ the differences between the resting membrane potentials and the critical membrane depolariza- $\vec{\omega}$ tions; their mean value was $73.3 \pm 1.5 \mathrm{mV}$.

In 30 of the fibres stimulated it was possible to measure the amplitudes of the action potentials; the mean value was $104.1 \mathrm{mV}$. It can be seen from Fig. 3B that the range of results obtained, from $80 \mathrm{mV}$ to $117 \mathrm{mV}$, is larger than might have been anticipated for a homogeneous population of muscle fibre Although in every case the action potential displayed an overshoot, the possibility nevertheless exists that the lowest values-for example, 80, 87, $89 \mathrm{mV}$-mas have been obtained from damaged fibres. For the reason the true mean amplitude may actually b rather higher than the calculated one.

MEMBRANE TIME CONSTANT AND INPUT RESISTANCE The mean value of the membrane time constant found in these experiments was $6.3 \pm 0.4 \mathrm{msec}(19$ fibres); the individual results are presented in Figure 4A. One further membrane constant, the input resistance, was measured in this study; it had a mean value of $2.7 \pm 0.2 \times 10^{5} \Omega$ (19 fibres, see Fig. 4B).

The results of the various types of investigation are summarized in Table III which also includes, for

TABLE II

REPORTED VALUES OF MEAN RESTING MEMBRANE POTENTIAL IN HUMAN SKELETAL MUSCLE FIBRES.

\begin{tabular}{|c|c|c|c|c|c|}
\hline Author & Method & Subjects (no.) & Impalements (no.) & Mean \pm S.E. $(m V)$ & Range ( $m V)$ \\
\hline $\begin{array}{l}\text { Bolte et al. (1963) } \\
\text { Brooks et al. }(1968) \\
\text { Creutzfeldt et al. (1963) } \\
\text { Elmqvist } \text { et al. }(1964) \\
\text { Goodgold et al. }(1966) \\
\text { Hofmann, et al. }(1966) \\
\text { Johns (1960) } \\
\text { Ludin (1967) } \\
\text { McComas et al. (1968) } \\
\text { Norris (1962) }\end{array}$ & $\begin{array}{l}\text { in vivo, cannula } \\
\text { in vivo, cannula } \\
\text { in vivo, open } \\
\text { in vitro } \\
\text { in vivo, cannula } \\
\text { in vitro } \\
\text { in vivo, open } \\
\text { in vitro } \\
\text { in vivo, open } \\
\text { in vivo, open }\end{array}$ & $\begin{array}{r}19 \\
9 \\
1 \\
16 \\
5 \\
4 \\
13 \\
3 \\
4\end{array}$ & $\begin{array}{r}200 \\
395 \\
26 \\
129 \\
93 \\
105 \\
40 \\
106 \\
134 \\
59\end{array}$ & $\begin{array}{l}87.2 \pm 0.4 \\
65 \pm 0.4 \\
87.4 \pm 1.8 \\
81.7 \pm 0.4 \\
77.5 \pm 1.2 \\
78.8 \pm 0.3 \\
77.8 \pm 2.4 \\
79.8 \\
83.6 \pm 0.5 \\
70.0 \pm 6.0\end{array}$ & $\begin{array}{l}\overline{46-90}^{*} \\
68-101 \\
70-90 \\
50-105^{*} \\
\overline{52-100 \cdot 5} \\
\overline{65-96} \\
\end{array}$ \\
\hline
\end{tabular}

*Low values rejected 
No.fibres

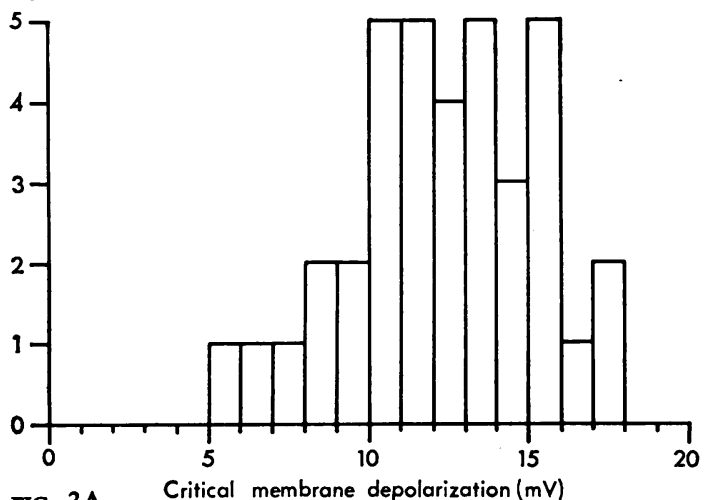

FIG. 3A.

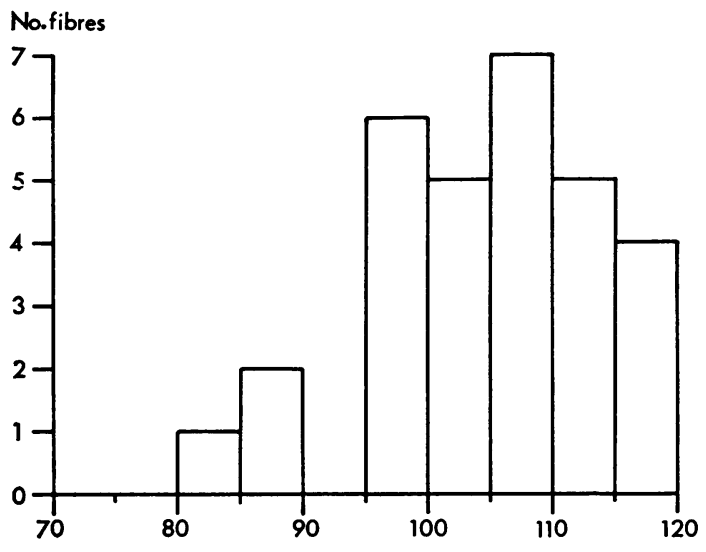

FIG. $3 B$. comparison, the corresponding mean values found for human intercostal muscle by Elmqvist, Hofmann, Kugelberg, and Quastel (1964).

\section{DISCUSSION}

CHOICE OF TECHNIQUE The investigative procedure of intracellular stimulation myography was first applied to excised human muscle by Elmqvist $e t$ al. (1960). Beránek (1964) described a method suitable for in vivo studies, in which a single micro-electrode formed part of a Wheatstone bridge circuit. The value of the intracellular stimulation procedure is that it enables a number of fundamental electrical properties of the membrane to be determined: these include the membrane time constant, the input resistance and the critical membrane depolarization. It is quite probable that in several disease states it will eventually be shown that these properties are abnormal. Indeed there is already evidence available to suggest that in one of these conditions, adynamia episodica, the changes in the electrical properties of the membrane are responsible for the evolution of the paralytic attacks (McComas et al., 1968).

The main problem of technique concerns the best way of introducing the micro-electrode into the muscle. Since the method adopted has a significant influence on the results, it is necessary to consider briefly each of the three techniques available at present. In the first method the muscle is excised and studied in vitro. The advantages are that the effects of

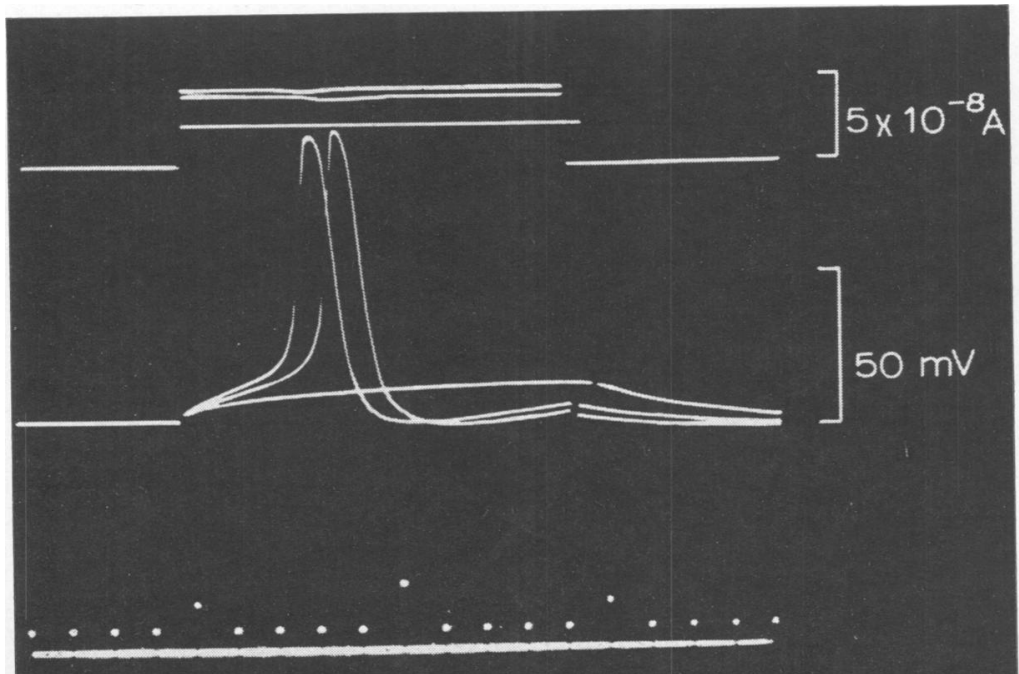

FIG. 3. A. Critical membrane depolarizations in 37 fibres; mean 11.8 S.E. $\pm 0.5 \mathrm{mV}$. $B$. Action potential amplitudes in 30 fibres; mean 104.1, S.E. $\pm 1.6 \mathrm{mV}$. C. Intracellular stimulation of muscle fibre; resting potential, $81 \mathrm{mV}$; critical membrane depolarization, $14 \mathrm{mV}$; action potential, $94 \mathrm{mV}$; membrane time constant, $6 \cdot 2$ msec; input resistance, $4.8 \times 10^{5} \Omega$. (Photograph retouched). 
TABLE III

MEMBRANE CONSTANTS DETERMINED FOR NORMAL HUMAN MUSCLE FIBRES AND EXPRESSED AS MEAN \pm STANDARD ERROR (NO. FIBRES)

\begin{tabular}{|c|c|c|c|c|c|}
\hline Muscle preparation & R.P. $(m V)$ & $T_{\mathrm{m}}$ (msec) & $R_{\text {in }}\left(\times 10^{5} \Omega\right)$ & C.M.D. $(m V)$ & Authors \\
\hline Intercostal in vitro & $81.5 \pm 0.4(129)$ & $18 \cdot 9 \pm 1 \cdot 2(7)$ & $5.7 \pm 0.4(28)$ & $7-20$ c. $28-33^{*}$ & $\begin{array}{l}\text { Elmqvist et al. } 1960,1964 \\
\text { *Hofmann et al. } 1966\end{array}$ \\
\hline Biceps, quadriceps in vivo & $83.6 \pm 0.5(134)$ & $6.3 \pm 0.4(19)$ & $2 \cdot 7 \pm 0.2(19)$ & $11 \cdot 8 \pm 0.4(37)$ & Present study \\
\hline
\end{tabular}

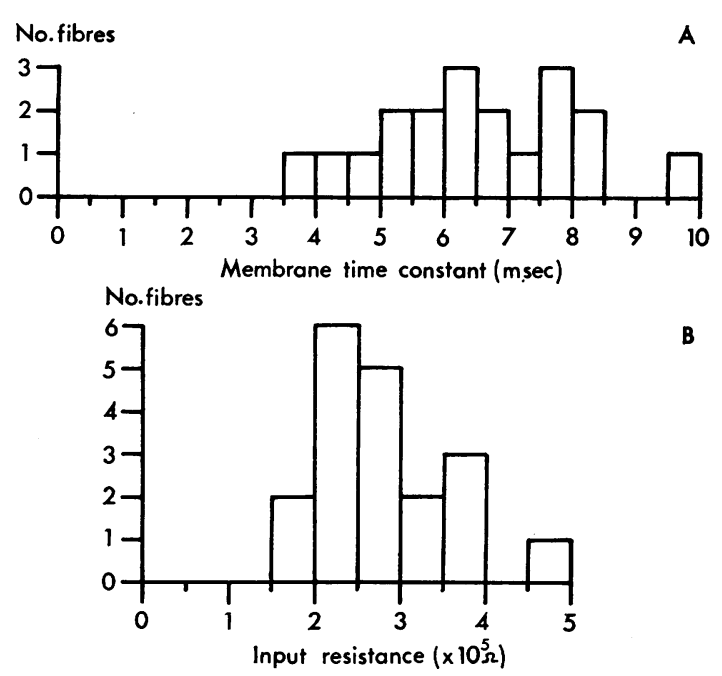

FIG. 4. A. Membrane time constants in 19 fibres; mean 6.3, S.E. \pm 0.4 msec. B. Input resistances in 19 fibres; mean $2 \cdot 7, \bar{S} . E$. $\pm 0.2 \times 10^{5} \Omega$.

changing the chemical environment of the muscle can be readily investigated, the mechanical stability of the recording system is potentially excellent and the fine anatomy of the muscle-for example, motor nerve branches - can be determined by microscopic examination of transilluminated muscle. The method has two disadvantages. Firstly, there are few muscles which are both accessible and sufficiently small to allow complete excision. A valuable exception to this is intercostal muscle; however, it appears from the results of the present study that some of the functional characteristics of intercostal muscle cannot be applied to limb muscles (see below). The second disadvantage of in vitro techniques is that certain in vivo properties of the muscle fibres may be lost. For example fibrillation potentials (Thesleff, 1962) and myotonic discharges (Hofmann et al. 1966) tend to disappear in vitro; furthermore, the resting membrane potential will be abnormally low unless the bathing medium contains protein (Kernan, 1963; McComas and Mossawy, 1965).
The second technique involves driving the microelectrode through a cannula which can be inserted into the muscle percutaneously. This technique has $\frac{\overline{0}}{\overline{0}}$ the great advantage of convenience. The most serious $\vec{\nabla}$ disadvantage is that the first few fibres encountered $\triangle$ by the electrode will almost certainly have been os damaged by the cannula. Although the results from $\vec{\circ}$ these fibres can be excluded (Table 2), the values $\overrightarrow{-}$ from deeper fibres are unreliable because changes of $\vec{\omega}$ tip potential may take place (Nastuk and Hodgkin, 1950; Del Castillo and Katz, 1955).

The third method is an 'open' one and has been $\dot{\omega}$ employed in the present study; micro-electrodes are $\overrightarrow{i r}$ inserted into the superficial fibres of muscles which have been exposed at operation. Provided the disse tion has been carefully carried out, even the most ? superficial fibres should be in good condition and there is no need to reject results. On the other hare the procedure is inconvenient for the subject, though ${ }_{0}$ it may be considered justifiable in patients whorequige a muscle biopsy.

In the present study we have been able to inves gate three young women in good health and with no 9 signs of muscle weakness. Two subjects were found to have no definite evidence of myopathy and may well have been normal. The third subject, A.B., was undoubtedly a carrier of the gene for Duchenne dystrophy. She had unquestionable myopathic $\stackrel{\complement}{\unrhd}$ changes in the muscle used for this investigation, $\overrightarrow{\vec{F}}$ although these were mild in comparison with those $\frac{3}{3}$ found in cases of Duchenne dystrophy. If there had been a 'dual population' of normal and dystrophic fibres in this subject, such as was postulated in carriers by Pearson, Fowler, and Wright (1963) on the basis of the Lyon hypothesis (Lyon, 1961), then $a^{0}$ bimodal distribution of resting membrane potentials 3 . might have been anticipated. Thus reduced muscle fibre resting potentials have been observed both in Duchenne dystrophy (Ludin, 1967) and in hereditary mouse dystrophy (Kleeman, Partridge, and Glaser, 1961; Lenman, 1963; McComas and Mossawy, $\frac{D}{0}$ 1965). Although there was evidence neither of a bimodal distribution nor of a reduction in mean N resting membrane potential, it is clearly desirable ${ }_{\text {N }}$ that further observations in carriers should be made 
before drawing firm conclusions regarding the presence or absence of a dual population of fibres. So far as the present investigation is concerned it would seem that, although none of the subjects can be accepted without reserve as normal, it is unlikely that the results obtained in them differ significantly from those which would have been derived if truly normal subjects had been investigated.

COMPARISON OF RESULTS It is clear from what has been said that the micro-electrode technique adopted must depend upon the type of information required and upon the clinical and technical facilities available. From Table II it is evident that the values of resting membrane potential obtained by the various techniques show very considerable differences since the means range from 65 to $87.4 \mathrm{mV}$. These differences may be partly accounted for by the choice of methods, but it is clear that results from different laboratories using the same technique may also differ widely. On the other hand, a comparison of results made in the same laboratory with identical techniques can be informative. Thus we have been able to show that the mean resting potential of human muscle is, within the limits of experimental error, identical with that of the mouse (83.6 and 82.7 $\mathrm{mV}$ respectively); (McComas and Mossawy, 1965). This measure of agreement in two widely different species raises the possibility that the resting membrane potentials are similar in other mammals.

The only studies which have provided information about the other membrane properties of human muscle are those on intercostal fibres by Elmqvist et al. (1964) and Hofmann et al. (1966). So far as the critical membrane depolarization is concerned, the values obtained by Elmqvist et al. (1964) $(7-20 \mathrm{mV})$ were of the same order as those found in the present investigation. In contrast to this, it would appear from the work of Hofmann et al. (1966) (cf. Fig. 4C and p. 535) that the critical membrane potential of myotonic and, by inference, normal fibres, may be as high as $\mathbf{2 8 - 3 3} \mathrm{mV}$. Such large values might be accounted for by the use of an in vitro technique; alternatively, they could indicate that the regenerative sodium conductance mechanism responsible for the action potential has a substantially higher threshold in some intercostal fibres compared with the limb muscle fibres investigated here.

The results in Table III also show that the membrane time constant is greater in intercostal than in limb muscle. Since the time constant is equal to the product of the specific membrane resistance, $R_{m}$, and the membrane capacitance, $C_{m}$, either or both of these parameters could be increased in intercostal muscle. The fact that the input resistance, $R_{i n}$, is also higher in intercostal muscle would suggest that it is the specific membrane resistance which is raised, since $R_{\text {in }} \propto \sqrt{ } \mathbf{R}_{\mathbf{m}}$.

On the other hand the results of the present study are in better agreement with those obtained in vivo from limb muscle in another mammalian species (McComas and Mossawy, 1966; mouse). In that study the critical membrane depolarization was $12 \cdot 3$ $\mathrm{mV}$, the membrane time constant $3.2 \mathrm{msec}$, and the input resistance $1.9 \times 10^{5} \Omega$. In an in vitro investigation of cat tenuissimus muscle Boyd and Martin (1959) obtained a membrane time constant of 4.8 msec at $37^{\circ} \mathrm{C}$, which agreed with the present study, though their values for the input resistances (3.7 to $7 \cdot 0 \times 10^{5} \Omega$ ) were considerably higher than ours.

In a subsequent paper (McComas et al., 1968) we shall present evidence to show that the membrane constants obtained in the present study are different from those in adynamia episodica.

\section{SUMMARY}

1. A micro-electrode study has been made of skeletal muscle fibres in three female subjects suspected of carrying the gene for Duchenne dystrophy. A subsequent evaluation of laboratory evidence suggested that two of these subjects were probably normal and that the third was a carrier.

2. Measurements were made of the resting potential, critical membrane depolarization, action potential amplitude, membrane time constant and input resistance. The results have been compared with those from other studies on mammalian skeletal muscle fibres.

3. A critical appraisal has been made of the methods at present available for the micro-electrode investigation of human muscle.

First, we must thank the three patients for their kind co-operation in this study and, secondly, Dr. J. N. Walton who has given continued encouragement and support. We also wish to acknowledge the help received from Dr. W. G. Bradley and Dr. H. B. Ghosh. Finally, we are heavily indebted to Sister M. Thompson and the neurosurgical nursing staff, to $\mathrm{Mr}$. C. Wallace and other technicians of the Regional Neurological Centre, and to Mrs. Y. Chisholm for secretarial assistance. The project received financial support from the Medical Research Council, the Muscular Dystrophy Group of Great Britain and the Muscular Dystrophy Associations of America, Inc.

\section{REFERENCES}

Adrian, R. H. (1956). The effect of internal and external potassium concentration on the membrane potential of frog muscle. $J$. Physiol. (Lond.), 133, 631-658.

Beránek, R. (1964). Intracellular stimulation myography in man. Electroenceph. clin. Neurophysiol., 16, 301-304. 
Bolte, H. D., Riecker, G., and Röhl, D. (1963). Messungen des Membranpotentials an einzelnen quergestreiften Muskelzellen des Menschen in situ Normalwerte. Klin. Wschr., 41, 356-359.

Boyd, I. A., and Martin, A. R. (1959). Membrane constants of mammalian muscle fibres. J. Physiol. (Lond.), 147, 450-457.

Brooks, J. E., and Hongdalarom, T. (1968). Intracellular electromyography. Arch. Neurol. (Chic.), 18, 291-300.

Creutzfeldt, O. D., Abbott, B. C., Fowler, W. M., and Pearson, C. M. (1963). Muscle membrane potentials in episodic adynamia. Electroenceph. clin. Neurophysiol., 15, 508-519.

Del Castillo, J., and Katz, B. (1955). Local activity at a depolarized nerve-muscle junction. J. Physiol. (Lond.), 128, 396-411.

Elmqvist, D., Hofmann, W. W., Kugelberg, J., and Quastel, D. M. J. (1964). An electrophysiological investigation of neuromuscular transmission in myasthenia gravis. Ibid., 174, 417-434.

$\longrightarrow$ Johns, T. R., and Thesleff, S. (1960). A study of some electrophysiological properties of human intercostal muscle. Ibid., 154, 602-607.

Fatt, P., and Katz, B. (1951). An analysis of the end-plate potential recorded with an intracellular electrode. Ibid., 115, 320-370.

Gardner-Medwin, D. (1968). Studies of the carrier state in the Duchenne type of muscular dystrophy. II. Quantitative electromyography as a method of carrier detection. J. Neurol. Neurosurg. Psychiat., 31, 124-134.

Goodgold, J., and Eberstein, A. (1966). Transmembrane potentials of human muscle cells in vivo. Exp. Neurol., 15, 338-346.

Hofmann, W. W., Alston, W., and Rowe, G. (1966). A study of individual neuromuscular junctions in myotonia. Electroenceph. clin. Neurophysiol., 21, 521-537.

Johns, R. J. (1960). Micro-electrode studies of muscle membrane potentials in man. Res. Publ. Ass. nerv. ment. Dis., 38, 704-713.

Kernan, R. P. (1963). Resting potential of isolated rat muscles measured in plasma. Nature (Lond.), 200, 474-475.

Kleeman, F. J., Partridge, L. D., and Glaser, G. H. (1961). Resting potential and muscle fiber size in hereditary mouse muscle dystrophy. Amer. J. Phys. Med., 40, 219-224.

Lenman, J. A. R (1963). Micro-electrode studies in muscle disease, pp. 230-239 in Research in Muscular Dystrophy: Proceedings of $\frac{\overline{ }}{-}$ the Second Symposium of the Muscular Dystrophy Group, $Z$ Pitman Medical, London.

Liley, A. W. (1956). An investigation of spontaneous activity at the neuromuscular junction of the rat. J. Physiol. (Lond.), 132, 응 650-666.

Ludin, H. F. (1967). Micro-electrode study of normal and dystrophic human muscle, In International Meeting on Electromyography (Abstracts). Glasgow.

Lyon, M. F. (1961). Genetic factors on the X-chromosome. Lancet, 2, 434.

McComas, A. J., and Mossawy, S. J. (1965). Electrophysiological investigation of normal and dystrophic muscles in mice,pp. 317341 In Research in Muscular Dystrophy: Proceedings of the. Third Symposium of the Muscular Dystrophy Group. Pitman Medical, London.

- (1966). Excitability of muscle fibre membranes in dystrophic mice. J. Neurol. Neurosurg. Psychiat., 29, 440-445.

—- and Mrozek, K. (1968). The electrical properties of muscle fibre음 membranes in dystrophia myotonica and myotonia congenita. $\bar{\sigma}$ Ibid., 31, 441-449.

- - and Bradley, W. G. (1968). The nature of the electro- $\varrho$ physiological disorder in adynamia episodica. Ibid., 31, 448-

Nastuk, W. L., and Hodgkin, A. L. (1950). The electrical activity of single muscle fibres. J. Cell. comp. Physiol., 35, 39-73.

Norris, F. H. Jr. (1962). Unstable membrane potential in humanmyotonic muscle Electroenceph. clin. Neurophysiol., 14, 197-201. W

Pearson, C. M., Fowler, W. M., and Wright, S. W. (1963). X-chromoe some mosaicism in females with muscular dystrophy. Proc. Nat. Acad. Sci. (Wash.), 50, 24-31.

Thesleff, S. (1962). Spontaneous electrical activity in denervated rat $\omega$ skeletal muscle, pp. 41-51. In The Effect of Use and Disuse on. Neuromuscular Functions, edited by E. Gutmann and P. Hnik. Elsevier, Amsterdam.

Walton, J. N., and Pennington, R. J. T. (1966). Studies on hunnin muscular dystrophy with particular reference to methods of carrier detection. Ann. N.Y. Acad. Sci., 138, 315-328. 